\title{
Does Ignorance Really Produce Irresponsible Behavior?
}

\author{
G. David Demetral, MA
}

\begin{abstract}
One of the major concerns voiced by parents/teachers considering consenting to the provision of sex education for their children is whether the provision of this service will stimulate their children to act more socially inappropriate than if the topic were avoided. The purpose of the present investigation was to compare resultant sexual behavior(s) of institutionalized developmentally disabled with their behavior(s) prior to the introduction of sex education and counseling. The result indicates that the students did not become more inappropriate, in fact on a number of measures they improved.
\end{abstract}

Perhaps the problems and suffering related to sex are greatest for the developmentally disabled. While most developmentally disabled persons have the same natural, normal sexual desires as the non-developmentally disabled, society refuses to consider the sexuality of the developmentally disabled person except in a negative manner.

Today a majority of the developmentally disabled are living in the community, whereas 50 years ago, the majority were living in institutions, and efforts are being made to provide a more normal social atmosphere for all developmentally disabled. They are now attending social gatherings, work in sheltered workshops, and participate in a variety of community placements.

Sengstock ${ }^{1}$ outline four problems most frequently mentioned by parents concerning the sexual behaviors of their developmentally disabled children; (1) the parents inability to answer adequately the questions raised by their children; (2) sexually oriented behavior excesses like masturbation; (3) fear that their child may become the "dupe" of immoral persons; and (4) fear that their own child may become a "danger" to other children in the community. These concerns and

G. David Demetral is with the Institute for the Study of Mental Retardation and Related Disabilities, University of Michigan, 130 South First Street, Ann Arbor, MI 48104. Requests for reprints should be directed to him. 
others are stimulating increased parental concerns about how to handle these "sexual" situations and they look to us as professionals for help, and we as professionals must now create data and techniques which allow us to effectively educate and advise, not only the parent, but the developmentally disabled person also.

One of the major concerns I have heard voiced in every parent/teacher group I am involved in, and which is not included in Sengstocks ${ }^{1}$ list, is that the provision of this educational and advising service will in fact stimulate their children to act in more socially inappropriate ways than if the subject was completely avoided. Professionals in the sex education field counter such a fear by alluding to the fact that it is ignorance that stimulates irresponsible behavior, not knowledge. Although I am certain that most educators and therapists would support this view, without outcome data, our support remains purely subjective.

The purpose of the present investigation was to compare the resultant sexual behavior(s) of institutionalized developmentally disabled persons with their behaviors prior to the introduction of sex education and counseling, in an attempt to provide that outcome data. Specifically, the investigation had the following six objectives:

1. In the six month period post-training would participants decrease or increase the frequency of confirmed incidents of sexual assaults from the baserates obtained during the six month period prior to training?

2. In the six month period post-training would the participants increase or decrease the amount of staff time required for individual counselling for sexual behaviors (i.e., masturbation in public, poor feminine hygiene, etc.) from the baserates obtained during the six months prior to training?

3. In the six month post-training would the participants increase or decrease the frequency of required pregnancy examinations from the baserates obtained prior to training?

4. Would the participants increase or decrease venereal disease examination recidivism post-training?

5. Would participants increase or decrease the number of participant initiated requests for contraception post-training?

6 . In the six month period post-training would the participants increase or decrease personal hygiene (as measured by the living unit data collection percentage system)? 


\section{PROCEDURE}

\section{Subject Population}

The subject population consisted of fourteen residents. Eight of the subjects were male and six were females. All 14 residents had reported IQ scores of less than 70, as measured by either the WAIS or WISC. To be selected the subject must: (a) have been enrolled and completed one of the two sex education courses offered; or (b) be currently enrolled in one of the courses. All persons in the sample had reached or passed puberty and raged in age from 14 to 36 years.

\section{Consent}

Consent forms were signed by the parent/guardian if the subject was a minor at the onset of the investigation.

\section{Setting}

The analysis was carried out on the living units of an exceptional Young Adult Behavior Adjustment program on the State Hospital campus.

\section{Design}

The quasi-experimental design which was used was the Archival Analysis of Historical Documents ${ }^{2}$. This design lends itself to the analysis of the ongoing, continuing historical records of an institution. Besides the low costs of aquiring the massive amount of potentially pertinent data necessary for the investigation, the other advantage of the archival analysis was its nonreactivity. Because the data base of concern for this investigation was confidentially recorded periodically it meets the criteria for historical documents.

\section{Methods}

In order to assess acquisition of information originally learned in either of the programs the experimenter analyzed the documented results in the programs Sex Education Tracking Folder or those recorded in the residents individual Problem Oriented Record at the time of training. (All residents met at least 85 percent mastery criteria for information acquisition.)

Individual sexual behavior data were obtained by actually visually reviewing the staff entries into the interdisciplinary notes of each clients Problem Oriented Record and/or the clinical/laboratory evaluation sections of this document. Representatives parameters were then recorded on one of six previously designed data sheets for the period of six months prior to and six months posttraining. 
Table 1

Confirmed Sexual Assaults

\begin{tabular}{rccr}
\hline $\begin{array}{c}\text { Subject } \\
\text { Number }\end{array}$ & $\begin{array}{c}\text { Measurement 1 } \\
\text { Pretest }\end{array}$ & $\begin{array}{c}\text { Measurement } 2 \\
\text { Posttest }\end{array}$ & D(1-2) \\
\hline 1 & 0 & 0 & 0 \\
2 & 0 & 0 & 0 \\
3 & 0 & 0 & 0 \\
4 & 0 & 0 & 0 \\
5 & 4 & 0 & 4 \\
6 & 1 & 0 & 1 \\
7 & 0 & 0 & 0 \\
8 & 0 & 0 & 0 \\
9 & 0 & 0 & 0 \\
10 & 0 & 0 & 0 \\
11 & 0 & 0 & 0 \\
12 & 0 & 0 & 0 \\
13 & 0 & 0 & 0 \\
& & & $\sum \mathrm{D}=5$ \\
& & & $\mathrm{~N}=17$ \\
& & & $\mathrm{~N}=13$
\end{tabular}

$t=.72 \quad \mathrm{df}=12 \quad \propto .05=2.160>.72$,

decrease in sexual assaults

\section{RESULTS (BY OBJECTIVE)}

\section{Objective 1}

As can be seen in Table 1, only two of the subjects had any confirmed sexual assaults. (These assaults consisted primarily of physical attempts to force either staff or residents to engage in sexual acts against their will). Although these two subjects decreased their sexual assaultive behavior from 4 to 1 and 1 to 0 , respectively, the group as a whole did not change assaultive behavior (t computed $.72<2.160$, $\mathrm{df}=12, \propto=.05)$. 


\section{Objective 2}

The data in Table 2 does in fact indicate significant decreases in staff counselling time for sexual behaviors (t computed 2.65 $>2.365, \mathrm{df}=12$, $\propto=.05$ ). When considering individual change it should be noted that only one subject required "more" counselling time after sex education than before. As a group, staff counselling time decreased by 100 minutes or 29.6 percent between the pre- and post-measurement periods.

\section{Objective 3}

Only six subjects appear in Table 3 for this analysis because there were only six females eligible for analysis. With the exception of two subjects, all significantly decreased the number of required visits to the gynecologist for pregnancy examinations (t computed 2.60>2.571, $\mathrm{df}=12, \propto=.05$ ). As a group the female subjects decreased their frequency of examinations by 68 percent after training in sex education.

Table 2

Staff Counselling Time for Sexual Behavior

\begin{tabular}{|c|c|c|c|}
\hline $\begin{array}{l}\text { Subject } \\
\text { Number }\end{array}$ & $\begin{array}{c}\text { Measurement } 1 \\
\text { Pretest }\end{array}$ & $\begin{array}{c}\text { Measurement } 2 \\
\text { Posttest }\end{array}$ & $\mathrm{D}(1-2)$ \\
\hline $\begin{array}{l}1 \\
2 \\
3 \\
4 \\
5 \\
6 \\
7 \\
8\end{array}$ & $\begin{array}{l}20 \mathrm{~min} . \\
30 \mathrm{~min} . \\
70 \mathrm{~min} . \\
35 \mathrm{~min} . \\
40 \mathrm{~min} . \\
40 \mathrm{~min} . \\
120 \mathrm{~min} . \\
30 \mathrm{~min} .\end{array}$ & $\begin{array}{r}0 \mathrm{~min} . \\
10 \mathrm{~min} . \\
120 \mathrm{~min} . \\
10 \mathrm{~min} . \\
20 \mathrm{~min} . \\
0 \mathrm{~min} . \\
90 \mathrm{~min} . \\
25 \mathrm{~min} .\end{array}$ & $\begin{array}{r}20 \\
20 \\
-50 \\
25 \\
20 \\
40 \\
30 \\
5 \\
5 \\
\Sigma \mathrm{D}=110 \\
\Sigma D^{2}=6925 \\
\mathrm{~N}=\quad 8\end{array}$ \\
\hline
\end{tabular}

$\mathrm{t} 2^{5} 2.65 \quad \mathrm{df}=7 \quad \propto .05=2.365<2.65$, significant

Staff Counselling Time

group total pre $=385$ minutes

decrease of $29.6 \%$

group total post $=275$ minutes 


\section{Objective 4}

As we can see in Table 4, the frequency of venereal disease examinations did not decrease significantly (t computed $0<2.160, \mathrm{df}=$ 12, , $=.05$ ). As a group the subjects only decreased the frequency of visits to the doctor for examinations by 8 percent. Inherent in the definition is a confusing feature worth mentioning. Due to oversight, the experimenter did not record those examinations whose outcomes were positive either before or after the training occurred.

\section{Objective 5}

As with the data presented in Table 1 (sexual assaults) the tabled data can be misleading (See Table 5). For although three subjects either requested some form of contraception, or a change in their present form of contraception, ten subjects contraception requesting behavior did not change at all, and because those three subjects changed their behavior from 0 to 2,0 to1, and 0 to 1 respectively, the noted group increase results (t computed 4.66>2.16, df, $\propto=.05$ ).

\section{Objective 6}

The data in Table 6 indicates significant changes in residents hygiene behavior ( $t$ computed 15.07>2.160, df $=12, \propto=.05$ ). Again, it

Table 3

Required Pregnancy Examinations

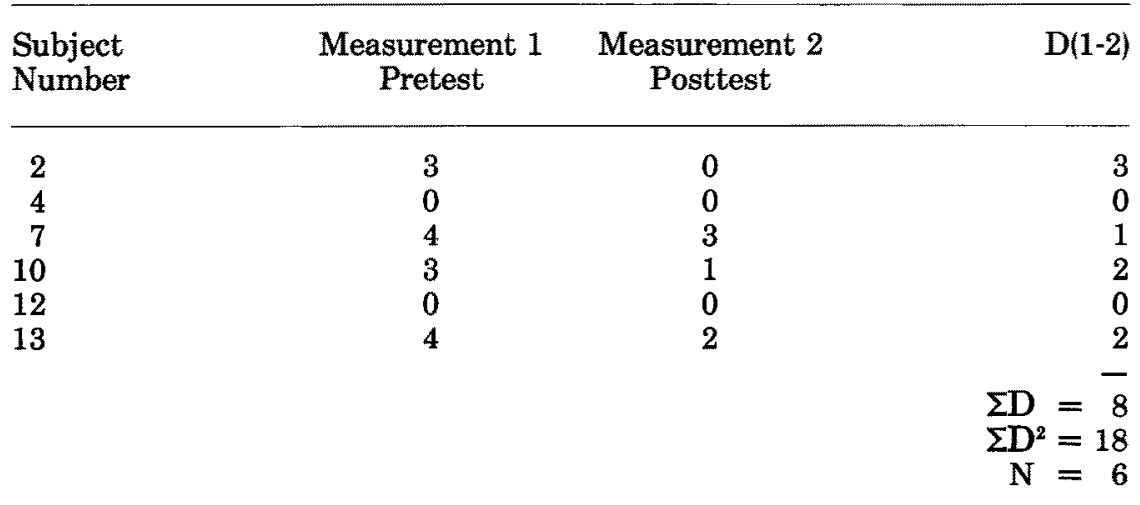

$t=2.6 \quad d f=5 \quad \in .05=2.571<2.60$, significant

Decreased by $68 \%$ 
Table 4

Venereal Disease Examinations

\begin{tabular}{lccr}
\hline $\begin{array}{l}\text { Subject } \\
\text { Number }\end{array}$ & $\begin{array}{c}\text { Measurement } \\
\text { Pretest }\end{array}$ & $\begin{array}{c}\text { Measurement } 2 \\
\text { Posttest }\end{array}$ & $\mathrm{D}(1-2)$ \\
\hline 1 & 0 & 1 & -1 \\
2 & 3 & 2 & 1 \\
3 & 1 & 1 & 0 \\
4 & 0 & 0 & 0 \\
5 & 0 & 0 & 0 \\
6 & 2 & 1 & 1 \\
7 & 2 & 0 & -1 \\
8 & 1 & 2 & 0 \\
9 & 0 & 0 & -2 \\
10 & 0 & 2 & 0 \\
11 & 0 & 0 & 1 \\
12 & 0 & 0 & -1 \\
13 & 3 & 2 & - \\
14 & 1 & 2 & $\sum \mathrm{D}=0$ \\
& & & $\mathrm{~N}=14$ \\
& & & \\
\end{tabular}

$t=0 \quad \mathrm{df}=13 \quad \propto 0$, not significant

Decreased by $8 \%$

should be noted that seven of the students either had no change (which is good), or actually got worse in their personal hygiene habits after training.

\section{DISCUSSION}

The present study attempted to illustrate that developmentally disabled persons do not emit more sexually undesirable behavior after exposure to sex education and counselling than those same students did prior to exposure. This fact is alone supported by the data from objective 1 which showed no increases in sexual assaults, in fact there was a decrease in two of the subjects post-training. Also, as can be seen by analyzing the data of objective 2 , the staff time necessary to counsel the students for behaviors like masturbation in public and inappropriate use of feminine hygiene materials decreased after train- 
Table 5

Request for Contraception

\begin{tabular}{|c|c|c|c|}
\hline Subject & Measurement 1 & Measurement 2 & $\mathrm{D}(1-2)$ \\
\hline 1 & 0 & 0 & 0 \\
\hline 2 & 0 & 2 & 2 \\
\hline 3 & 0 & 1 & 1 \\
\hline 4 & 0 & 0 & 0 \\
\hline 5 & 0 & 0 & 0 \\
\hline 6 & 0 & 0 & 0 \\
\hline 7 & 0 & 0 & 0 \\
\hline 8 & 0 & 0 & 0 \\
\hline 9 & 0 & 1 & 1 \\
\hline 10 & 0 & 0 & 0 \\
\hline 11 & 0 & 0 & 0 \\
\hline 12 & 0 & 0 & 0 \\
\hline 13 & 0 & 0 & 0 \\
\hline \multirow[t]{4}{*}{14} & 0 & 0 & 0 \\
\hline & & & \\
\hline & & & $\begin{array}{l}\Sigma D=4 \\
\Sigma D^{2}=6\end{array}$ \\
\hline & & & $\mathrm{N}=14$ \\
\hline
\end{tabular}

$\mathrm{t}=4.66 \quad \mathrm{df}=13 \quad \propto .05=2.16<4.66$, significant

Increased

ing by 29 percent. Also the data which indicate decreases in the number of required pregnancy examinations, and increased personal hygiene are wonderful indicators that the students actually became more responsible after training than they appeared to be before training.

Although these results are quite promising, I feel there is a strong need to do much more research on the resultant behavioral effects of sex education and counselling on the developmentally disabled. Almost all the literature on this subject has been published within the last seven to ten years, and almost none of this can be properly classified as research. Most of the citations I came across while doing this investigation referred to theorizations rather than interpretations of data. During this investigation, it became apparent to me why little research has been reported. One reason must be the lack of any adequate procedures for evaluating a program of sex education for the developmentally disabled. For example, when considering the elimina- 
Table 6

Personal Hygiene

\begin{tabular}{lrrr}
\hline $\begin{array}{l}\text { Subject } \\
\text { Number }\end{array}$ & Pretest & Posttest & $\mathrm{D}(1-2)$ \\
\hline 1 & & & \\
2 & $82 \%$ & $90 \%$ & $+8 \%$ \\
3 & $90 \%$ & $90 \%$ & $0 \%$ \\
4 & $85 \%$ & $85 \%$ & $0 \%$ \\
5 & $80 \%$ & $75 \%$ & $-5 \%$ \\
6 & $\mathrm{~N} / \mathrm{A}$ & $\mathrm{N} / \mathrm{A}$ & $\mathrm{N} / \mathrm{A}$ \\
7 & $80 \%$ & $90 \%$ & $+10 \%$ \\
8 & $80 \%$ & $80 \%$ & $0 \%$ \\
9 & $90 \%$ & $90 \%$ & $0 \%$ \\
10 & $90 \%$ & $80 \%$ & $-10 \%$ \\
11 & $90 \%$ & $95 \%$ & $+5 \%$ \\
12 & $90 \%$ & $100 \%$ & $+10 \%$ \\
13 & $80 \%$ & $80 \%$ & $0 \%$ \\
14 & $80 \%$ & $90 \%$ & $+10 \%$ \\
& $80 \%$ & $73 \%$ & $-7 \%$ \\
& & & - \\
& & & $\mathrm{D}=\mathbf{2 1}$ \\
& & & $\mathrm{D}^{2}=563$ \\
& & $\mathrm{~N}=14$ \\
\hline
\end{tabular}

$\mathrm{t}=1507 \quad \mathrm{df}=13 \quad .05=2.160<15.07$ significant

tion of learning deficits which are accompanied by inappropriate sexual behavior, the investigator is confronted with issues not as easily identifiable or as easily controlled as those when measuring the acquisition of learning as determined by pre- and post-testing.

One of the major issues is the "dependency-independency" dichotomy of subject influence. When assessing acquisition of knowledge, the subject is in total control of his/her resultant performance, and when measuring resultant behavioral patterns as a consequence of education the student, in many cases, loses that degree of control. For example, when considering the parameters of required pregnancy examinations, or venereal disease examinations, it was the staff and not the resident in many cases, that scheduled the examinations. Also, many examinations are done on (staff determined) "high risk" individuals periodically for "safe" measure, regardless of their current behavioral patterns. Also, because the data for this study was recorded in the individual Problem Oriented Record, much information (that 
would be useful when conducting an analysis like this) is never recorded. An illustrative case will clarify my point. While analyzing the data on one of the units I heard a graduate of the sex education course ask if he could see the doctor because he thought he might have V.D. The staff then called the clinic, requested the examination, but did not record the resident "initiation" of that request which represents a very appropriate generalized response to training.

Another issue, is the method of a data analysis that the experimenter is forced to utilize. One of the most usable and at the same time least representative tools is the t-test of significance. As became apparent when considering requests for contraception, the t-test yielded very significant effects in spite of the fact that only two subjects behavior actually changed. In fact it appears that in a majority of the cases reported with the six behavioral parameters the effect of a few individuals not only masked the effects of the majority, but in fact influenced the results to a significant degree. It is for this reason that the t-test analysis was not the only method used and presented.

This is not to cast doubt upon the usefulness of the information presented. The next step is to expand/evaluate and reevaluate what has been initiated by this investigation.

The primary aim of sex education is to help each individual to understand himself/herself as a sexual being in the total sense and to use that knowledge in a responsible manner. Future research, then, must concentrate on making three important contributions to the problem of sex education of the developmentally disabled by providing:

1. More exact information on the specific needs of the developmentally disabled individual with regard to the biological, social, and psychological aspects of sexual development.

2. Further development of appropriate materials and methods for meeting these needs.

3. Improvement oriented evaluation of both long range and short range programs of sex education for the developmentally disabled.

\section{REFERENCES}

1. Sengstock WL: Sex Education for the Mentally Retarded. Paper presented at the Institute on Sex and the Mentally Retarded, Cleveland, Ohio, May, 1967.

2. Webb EJ, Campbell DT, Schwartz RD, Sechrest L: Unobstrusive Measures: NonReactive research in the Social Sciences. Rand McNally, Chicago, 1966. 